\title{
Razón «débil» y Educación «light»
}

\author{
ENRIQUe Gervilla CASTILlo \\ Universidad de Granada
}

\begin{abstract}
SUMMARY.-The «strong» reason, which characterises the theocentric and anthropological philosophical systems of the middle ages and modernity, has been broken faced with the «un-reason» seen in the disasters of manking: war, hunger, armaments, social inequality... In consequence «weak» reason which belongs to the postmodernity is now prevalent in a large part of our society.

Ontological fragmentation and «weak» thought have engendered a new way of living whose influence is seen in education which is based on relativism and individualism.

The causes of this change and its positive and negative aspects are critically analyzed in this article.
\end{abstract}

\section{INTRODUCCIÓN}

Buena parte de nuestra sociedad actual, de modo especial los jóvenes, han fundamentado su vida, a veces inconscientemente, en el «pensamiento débil» y en la fragmentación ontológica de la postmodernidad. Este talante y modo de vida genera una nueva mentalidad, unos nuevos valores y, en consecuencia, una nueva cultura y educación (denominada «light») a veces antagónica a la de hace sólo unas décadas.

En opinión de Chesterton con cada década se inaugura hoy un siglo. La estabilidad y firmeza de otras épocas históricas precedentes es ya sólo un recuerdo. Los cambios se suceden con tal rapidez que no hay nada que escape a la crisis. Heráclito ha ganado la batalla a Parménides, Nietzsche a Hegel, Dionisios a Prometeo, la Postmodernidad a la Modernidad. El enfrentamiento generacional, bastante generalizado entre jóvenes y mayores, tiene aquí su origen y explicación.

En las páginas que siguen pretendemos exponer el fundamento del desencanto y debilidad de la razón, propia de la postmodernidad, así como la educación «light» que de ese fundamento se deriva.

\section{LA RAZÓN «DÉBIL»}

La razón «fuerte», propia de los sistemas filosóficos teocéntricos y antropocéntricos de la Edad Media y la Modernidad, se ha mostrado impotente para explicar los desastres de la humanidad. De este modo, la confianza en la razón de la modernidad y del medievo, se quiebra para ingresar en los tiempos del pensamiento débil, inseguro y fragmentado. 
Los nuevos tiempos se inician, pues, con un desencanto y desconfianza de la razón, dado que la seguridad y confianza en ella depositadas desde el Renacimiento y la Ilustración, lentamente, se ha convertido en inseguridad, desconfianza, decepciones y desengaños. Promesas y realidades no se corresponden. La ilusión puesta en la ciencia, en la técnica, en la justicia e igualdad social, etc. no se ha logrado, o al menos no se ha logrado como se esperaba. Los avances han sido parciales y el progreso tecnológico está siempre acompañado de aspectos negativos, y, en consecuencia, será siempre un progreso amenazado y en beneficio de unos, utilizado, a veces, como dominio y poder sobre los demás. Por lo que no existe seguridad de que tales avances «hayan convertido al sujeto humano en más hombre, ni siquiera que la razón produzca racionalidad» (Mardones, 1989, 9). La historia de la razón es así la historia de los desengaños de la razón ${ }^{1}$, o de lo «irracional» de la razón.

Aquel «sapere aude» que liberaba al hombre de las ataduras religiosas de la Edad Media (Kant, 1981, 25), es sustituido ahora, en el pensamiento postmoderno, por un segundo «sapere aude» que lo libera ahora de las ataduras de la modernidad. Aquella razón ilustrada con pretensiones de verdad, de totalidad y de objetividad, es desde comienzo de siglo y especialmente en estas últimas décadas, menos verdad y más verdades, menos total y más parcial, menos objetiva y más subjetiva. La razón ha perdido credibilidad para decirnos con seguridad qué es la realidad o qué es el hombre, y, en consecuencia, es el momento de la retirada; se impone la «sensatez racional» del conformismo, lo limitado, la humildad intelectual. Desde esta visión son suficientemente significativos títulos de obras tales como:

- «El pensamiento débil» de Vattimo-Rovati.

- El eclipse de la razón» de Adorno-Horkheimer.

- «Asalto a la razón» de Lukacs.

- «El conocimiento inútil» de Revel.

- «Adiós a la filosofía» de Cioran.

- «La derrota del pensamiento» de Finkielkraut.

- «La era del vacío» y «El imperio de lo efímero» de Lipovetsky.

- «Adiós al progreso» de Campillo.

- «La crisis de la razón» de Jarauta.

- «La razón sin esperanza» de Muguerza.

- «La miseria de la razón» de Reguera ... y un largo etcétera.

Desde esta opción, cada vez más en auge, buena parte de la clase intelectual se han subido al carro del agnosticismo, convirtiéndose éste en una especie de moda, de denominador común e incluso de valor intelectual. La mayor parte de la filosofía española que se considera postmoderna -en opinión de Carlos Díaz- pertenece a este ámbito.

1. La reducción del saber a categorías racionales condujo a la identificación entre razón y ser. Así lo vieron Parménides y Heráclito, pasando por Platón, Aristóteles y Hegel... y hasta nuestros días. La modernidad no hará sino afirmar con fuerza tal procedimiento (...). Se aceptó sin más que lo normal es pensar racionalmente, cuando se da por sentado que «normal» ya equivale a «racional». Pues bien, la postmodernidad viene a romper esta tautología o círculo vicioso del que no es fácil liberarse. Pensar debería suponer cuestionar la racionalidad misma; poner en entredicho el empleo de la «inteligencia» (Pardo, J., «Filosofía y clausura de la modernidad». En Revista de Occidente, 1986, $\mathrm{n}^{\circ}$ 66, pp. 39-40). 
«Muchos de los cuales se han atribuido el nombre de postmodernos apenas la nomenclatura fue puesta a circular en el mercado de ideas» (Díaz, 1985, 79). Se trata de un agnosticismo de una cierta cautela e inseguridad frente a las cuestiones religiosas y metafísicas, con el convencimiento de que sobre esos temas no se puede saber nada, y que al mismo tiempo propugna un humanismo que, superando las polémicas fe-ateísmo, favorezca el entendimiento, la tolerancia y la colaboración social. Tal situación -comenta Javier Sádaba- es tan generalizada que "no causa siquiera curiosidad; lo normal y extendido en nuestros días es que el hombre adulto y razonablemente instruido no es un creyente o un incrédulo, sino que se despreocupa de tales cuestiones» (Sádaba, 1984, 80). Sólo la finitud constituye el límite y posibilidad de explicar la realidad, pues los límites de la finitud son los límites del ser (Tierno, 1976, 76).

Junto a este agnosticismo intelectual, otro agnosticismo, llamado «popular inducido», derivado de la mentalidad positivista y de la visión empirista de la vida, se extiende cada vez más entre todas las capas de la sociedad. Así, el agnosticismo, de manera más o menos expresa, es una «forma mentis» del hombre actual, posible de constatarse en cualquier opinión reinante.

El desencanto de la razón y la debilidad del pensamiento ha generado también un «pasotismo», más visible en la vida y vocabulario de los jóvenes. El «yo paso, tío» es una afirmación negativa de desentenderse, de no participar, de no actuar. Es una actitud de tránsito, de paso, semejante a la vida de los aeropuertos: son lugares de paso que no vinculan establemente. El «pasota» no entra en el juego, no le interesa, bien porque no tiene ganas, o no tiene baza que jugar. Hay que pasar de instituciones: colegios, política, religión, sindicatos... ¿Para qué? No existen ya razones fuertes para convencer e ilusionar.

El postmoderno se instala así cómodamente en el pensamiento débil. Lo que hoy pienso y siento, no sé si lo mantendré mañana. Como en un supermercado, cada cual elige, en el momento, lo que le apetece, sin temor a la incoherencia y sin pretender refutar nada. La razón desencantada es ya tan flaca que ha perdido la fuerza de la razón para romperse en mil razones.

En nuestra infancia todos escuchábamos atentos el cuento de la lechera. Quizás sea éste un gráfico cuento para expresar el paso de la modernidad a la postmodernidad. La ilusión de la lechera haciendo sus razonamientos económicos, se deshizo tras la realidad de la ruptura del cántaro. A partir de este momento la vida de la lechera será distinta: desencanto, escepticismo y pasotismo. Sin añoranza ni tristeza, la lechera postmoderna ya no pensará en el futuro, recogerá los trozos del cántaro roto que más le agraden y, desde ello, sólo vivirá el presente.

\section{Múltiples fundamentos}

Ante el desencanto de la razón todo es posible. Si antes el ser se decía de mucha maneras, ahora se puede decir de muchas cosas; más que un ser hay múltiples seres. La pérdida del fundamento ha ocasionado la fragmentación y el nacimiento de múltiples fundamentos. Han terminado los grandes principios de la modernidad. Nos movemos en una pluralidad de formas de justificación. "Todos los comportamientos pueden cohabitar sin excluirse, todo puede escogerse a placer, lo más operativo como lo más exótico, 
lo viejo como lo nuevo, la vida simple-ecologista como la vida hipersofisticada, en un tiempo desvitalizado sin referencia estable, sin coordenada mayor» (Lipovetsky, 1990, 41).

Nuestra sociedad, la sociedad postmoderna es, así, globalmente «irracional» como resultado de muchas racionalidades parciales. Hemos pasado de la mayúscula a las minúsculas en todos los órdenes de la vida, desde los fundamentos vitales hasta las instituciones. Y las mayúsculas que aún permanecen, sólo son mayúsculas para cada uno (Lozano, 1989, 25). Esta disolución crea una situación de temporalidad en las vinculaciones sociales, una des-orientación cara al futuro, y una desvalorización de aquellos valores supremos o suprahistóricos de la modernidad. No vivimos en una sociedad sin valores, como a veces oímos comentar, más bien vivimos en una sociedad que, al poseer otros valores, hace inválidos los de la generación precedente. O mejor, quizás, sería decir que al convivir unos y otros, se hace difícil, cuando no imposible, distinguir con claridad el valor del antivalor. Ya que el fundamento no existe, pues no hay argumentos para justificar un único fundamento.

Para describir tal destrucción, son ilustrativas las imágenes utilizadas al respecto: $E l$ búcaro roto (C. Díaz), la sustitución de la brújula por el radar (J. M. Lozano), mar abierto sin horizonte fijo, ni fundamento (Mardones), sendas perdidas (Heidegger), islas de un archipiélago (Lyotard), carretera sin indicadores, barco sin ancla, espejo roto... ${ }^{2}$. Desde esta situación plural y de carencia, la razón misma elaborará su hoja de ruta, buscará su indicador y construirá su fundamento, o bien se unirá a aquella parte del espejo roto o del búcaro quebrado que más le satisfaga.

La postmodernidad, de este modo, dice adiós a todo fundamento y a los grandes principios fijos para abrirse a una nueva «episteme» de indeterminación, discontinuidad y pluralismo. Sus consecuencias sociales son visibles en:

a) La pérdida de la centralidad de la religión: salvación, destino del hombre, pecado, gracia..., ocupando su lugar los problemas económicos que, cómo producir, qué beneficios obtener. Sustitución, en consecuencia, de los valores religiosos por valores económicos.

b) Un mundo de cosmovisiones fragmentadas al desaparecer la cosmovisión cristiana en Occidente. A esta pérdida de la sacralidad Weber denominó «desencantamiento del mundo» ${ }^{3}$.

c) Una creciente burocratización, derivada del crecimiento industrial y económico, pues se hace necesario introducir orden para clasificar y subclasificar organismos cada vez más complejos en la vida social y política (Mardones, 1989, 14-18).

2. El título de ciertas obras es asimismo bastante significativo: «La religión en fragmentos» (Fierro, A.), «La voluntad de fragmento» (Reyes, R.), «Crónica de ideas perdidas» (Chatelet, T.), «Escritos politeístas» (Savater, F.), «Todos los héroes han muerto» (Albiac, G.)...

3. Tal pérdida puso de manifiesto un proceso de diferenciación de la razón. La razón aparecía conteniendo diversas dimensiones: la científica, orientada al conocimiento de las leyes de la naturaleza; la ético-política, dirigida a la reflexión de la vida de los hombres en colectividad; y la estético-expresiva, que mira al yo y a lo que le rodea en cuanto poseedor de formas bellas. La razón ahora parece plural y la pregunta es si existe posibilidad de comunicación entre las diversas dimensiones o esferas de la razón. Los teóricos críticos, como Habermas y sus discípulos, ya se plantearon el tema del diálogo y la posibilidad de comunicación de las diversas racionalidades sin caer en la seducción de ninguna de ellas. 
El cuento indio, narrado por el profesor Maurice Duverger, puede ilustrar la fragmentación que conlleva la pérdida del fundamento. Se trata de la descripción, por medio del tacto, de un elefante por cinco invidentes. El primero tocó la trompa y dijo: «es un tubo». El segundo agarró la pata: «Es un tronco de árbol». El tercero cogió el rabo: «Es una cuerda», sentenció. El cuarto palpó un colmillo: «Se trata de una estaca». El último chocó con el cuerpo y exclamó escéptico: «ßBah, sólo es un muro!» (Cebrián, 1987, 9).

Al postmoderno no le preocupa cual sea la realidad total, se contenta con la parcialidad que momentáneamente percibe. De este modo, su vida es un reino de subjetividad autónoma, sin norte, ni orientación predeterminada. Lipovetsky $(1990,36)$ afirma al respecto: «Dios ha muerto, las grandes finalidades se apagan, pero a nadie le importa un bledo. Esta es la alegre novedad». O como sostiene Heidegger: vayamos por sendas perdidas y sólo encontraremos un pensamiento débil y fragmentado.

Hoy conocemos demasiado los fracasos históricos para afirmar con sẹguridad donde está la verdad o el ideal a seguir: en el continente ilustrado se dieron dos guerras mundiales, las ideologías marxistas han generado dictaduras y pobreza, el capitalismo permite convivir el derroche y la miseria... Ninguna ideología es sólida y fiable. Ningún relato merece nuestra confianza, llámense estos relatos liberales u obreristas, cristianos o humanistas, siempre nos encontramos con la legitimación del terror, de las diferencias, de la imposición militar o espiritual, del anonimato de los sometidos (Mardones, 1986, 6-8).

$\mathrm{Su}$ desaparición en modo alguno conlleva nostalgia o tristeza; al contrario, se vive con alegría y esperanza. La alegría de haberse liberado del peso de la verdad, de la razón, de la unidad, de la objetividad, de las grandes ideologías..., y la esperanza ante un horizonte libre y abierto a múltiples experiencias. En la muerte misma de los grandes relatos e ideologías surge el nacimiento de muchas historias pequeñas, que continúan tramando el tejido de la vida social y que iluminan aspectos parciales de la realidad, pero sin la pretensión de ofrecer una respuesta universalizante. En palabras de Lyotard $(1984,10)$ para la mayoría de la gente ha desaparecido la nostalgia del relato perdido.

Se trata de vivir ahora una situación diferente, de crisis, sospecha, incredulidad, desconfianza, que surge al abandonar la protección, la certeza, la seguridad, de los grandes discursos metafísicos que daban cuerpo a la modernidad. Con la postmodernidad se toma conciencia de la complejidad del ser humano y de la sociedad, de que no todo está estructurado, de que no existe un punto de vista único, ni un elemento clave para comprender y explicar la realidad. La fragmentación y el pluralismo son el destino insuperable del hombre de hoy como reacción a épocas «unificadoras» pasadas y también como consecuencia del nacimiento de campos que manifiestan distintas leyes de estructuración y funcionamiento, y que ocasionan el desarrollo de pluralidad de lógicas ${ }^{4}$.

4. «Las verdades relativas aparecen en un esquema combinatorio mucho más irónico que trágico. Las contradicciones son bienvenidas, no por aquello de la síntesis dialéctica, sino porque, al parecer irresolubles, dan variedad y animación al mundo. Si toda verdad es algo falsa, toda mentira es algo verdadera» (Ramírez, J. A. «Catecismo breve de la postmodernidad» en Misión Abierta (1988-89) nº 4, p. 39). 


\section{EDUCACIÓN «LIGHT»}

La vida «light», como proceso y meta de formación, la encontramos presente y vigorosamente activa en el ámbito de la educación informal más que en los centros educativos. De aquí la incomodidad de muchos jóvenes y la cierta huida de las instituciones al no encontrar en éstos sus valores, deseos y aspiraciones. El divorcio entre la educación oficial y la educación fuera de la escuela (cine, radio, Tv., canciones, prensa, diversiones, etc.) ocasiona antagonismos de difícil solución.

Ante esta situación, la pregunta de muchos educadores es la siguiente: ¿Qué hacer? ¿Cómo formar en este antagonismo? ¿Cómo intervenir ante la debilidad del pensamiento y la fragmentación ontológica? La respuesta no es nada fácil, por cuanto hallamos tantas razones y objeciones para justificar o rechazar la modernidad como la postmodernidad. Resulta relativamente fácil, desde una visión determinada, argumentar o rechazar la opuesta. Sin embargo, no creemos que sea éste el mejor camino para esclarecer un modo de vida o ideal educativo. Nos inclinamos más bien por una búsqueda conjunta de la verdad y del bien que nos oriente hacia una determinada opción. Esta es imprescindible ante la pluralidad de modelos, por cuanto es imposible educar sin valores y sin modelo, pero reconozcamos que hoy no existe un modelo; más bien nos encontramos con una confluencia de múltiples modelos. Ni todos los modernos son totalmente modernos, ni los postmodernos totalmente postmodernos, ni los conservadores, ni los liberales.. lo son, salvo excepciones, íntegramente. Parece más constructivo, y por tanto educativo, aceptar la realidad plural existente, sometiendo a análisis crítico los valores que las distintas opciones ofrecen. En nuestro caso, el fundamento de la educación «light»: el relativismo e individualismo.

Hemos de agradecer a la postmodernidad la recuperación de ciertos valores olvidados al someter a crítica los fundamentos de la modernidad. Pero también aquélla debe ser criticada para juzgar su fundamento, así como las consecuencias individuales, sociales y educativas que de él se derivan ${ }^{5}$.

Educar en el relativismo, es educar en el pluralismo, en el pensamiento débil, y en consecuencia, en la secularización, la «desorientación», la tolerancia...

El racionalismo sobrevaloró la razón al hacer de ésta la diosa rectora de la vida y, por lo mismo, se «idolatró» el saber científico sin tener en cuenta sus limitaciones y peligros. La escuela, en consecuencia, se entregó «a los profetas de la ciencia y no de la educación» (Brezinka, 1990, 20), olvidando el aspecto afectivo y lúdico de toda formación. El eficientismo, la obsesión por el rendimiento y la tecnificación anularon o atrofiaron valores como la gratuidad, lo festivo, lo in-útil, el gusto por el saber mismo. Se olvidaron los orígenes del término griego «scholé», del latino «schola» y del verbo «sapere» que fueron el ocio, el descanso y el gusto por el saber ${ }^{6}$. El «homo faber» venció

5. Es importante recordar que el nacimiento de ciertos valores conlleva frecuentemente -y a veces necesariamente- la muerte de otros.

6. El término griego «scholé» del que se derivó el latino «schola» significó inicialmente ocio y descanso. El verbo saber y el sustantivo sabiduría tienen sus raíces en el verbo latino «sapere» que significa gustar, saborear. St. Tomás relacionó el saber especulativo con su incidencia afectiva cuando, al referirse al sentido etimológico de sabiduría, escribió: «Sapientia: discitur sapientia sicut sapida scientia», es decir, sabiduría como ciencia sabrosa, un saber con sabor (Gervilla, E., 
en la lucha contra el «homo ludens». Los programas escolares fueron predominantemente intelectualistas, enciclopédicos y memoristas, en los que «la letra con sangre entra» era componente de los mismos?

La educación postmoderna ha constatado el fracaso del racionalismo, del absolutismo cientista, del dogmatismo religioso... como incapaces de una orientación axiológica que lleve a los seres humanos a una mayor felicidad. En consecuencia, la nueva educación caminará, fuera de la escuela, por las sendas del pluralismo, la debilidad, el escepticismo, la secularidad, la afectividad... Lo que ahora nos cuestionamos es si, ante esta transmutación de valores, la educación postmoderna no queda tan mutilada y unilateral como la moderna, sólo que en sentido opuesto.

Si nadie, ni nada, es absoluto; nadie, ni nada, puede obligarnos absolutamente. Si el absolutismo ha llevado a la educación a fuertes dictaduras e imposiciones, el relativismo nos conduce -o puede conducirnos- a inseguridades, inestabilidades psicológicas y a enfrentamientos de unos contra otros. Si «todo vale», vale igualmente para el fuerte y para el débil, por lo que el fuerte (sabio, poderoso, rico) terminará imponiéndose, ante intereses opuestos, sobre el débil. La ley del más fuerte será la realidad.

El relativismo nos ha deparado la grandeza del pluralismo social, político y religioso, pero sin unas mínimas «ataduras» comunes la libertad y la misma vida serían privilegio de unos pocos: los fuertes y poderosos. La educación, o al menos la «buena educación», corre el riesgo de ser elitista, para los que tienen y pueden. La riqueza individual, que desde el relativismo se ofrece, se torna privilegio educativo de unos pocos y, por tanto, pérdida social para la mayoría. Sólo una educación sólida y basada en principios y valores firmes, pero al mismo tiempo flexible y tolerante, llegará a ser educación para todos. La verdad no se impone de otra manera que por la fuerza de la misma verdad. Cuanto menor es la fuerza de la verdad, mayor será su violencia impositiva y a la inversa.

Desde un politeísmo de valores no es posible acuerdo alguno sobre el bien ${ }^{8} \mathrm{y}$, por lo mismo, imposible afirmar en qué consiste «lo bueno». La educación necesariamente ha de ser «débil», con las ventajas del pluralismo y la tolerancia, pero también con los riesgos que tal educación conlleva de «desorientación» o de carencia de valores firmes (Camps, 1990, 131).

Finalmente, desde este relativismo axiológico, hemos de agradecer a la educación postmoderna el valor otorgado a la tolerancia, a la flexibilidad y a la actitud dialogante,

«La adquisición del valor saber, trabajo diario del escolar» en Education and work in modern society, Actas del $9^{\circ}$ Congreso Internacional, Universidad Complutense, Madrid, 1986, p. 473).

La agonía o enfrentamiento entre la razón y el sentimiento la expresó Antonio Machado en los siguientes versos:

«Dice la razón: Tú mientes

y contesta el corazón:

Quien mientes eres tú, razón

que dices lo que no sientes».

7. Recomendaciones egipcias: «El niño tiene espaldas; escucha cuando se le pega. Los muchachos tienen las orejas en los lomos, cuando se les pegan escuchan. El oído lo tiene el chico en el trasero; así escucha cuando se le pega» (Lozano Seijas, La escolarización, Montesinos, Barcelona, 1980, p. 11).

8. Sólo es posible acuerdos sectoriales con quienes coinciden en un mismo conjunto de valores. 
sin cuya vivencia se hace imposible la convivencia en una sociedad plural y democrática. Su presencia e importancia son hoy indiscutibles. Lo que sí nos cuestionamos es la raíz de estos fundamentos: La tolerancia, ¿no es consecuencia de la debilidad y de la indiferencia, en la que hay razones para todo porque no hay razones para nada? La flexibilidad, ¿no es en el fondo una carencia de convicciones profundas, de solidez y de coherencia? La actitud dialogante, ¿no es consecuencia de la imposibilidad metafísica? La misma afirmación absoluta de lo relativo, ¿no es ya una verdad absoluta?

El planteamiento de éstas y otras muchas cuestiones son quizás hoy más necesarias que nunca, si queremos escapar de la manipulación y del adoctrinamiento, y lograr una opción educativa crítica, responsable y libre.

Educar en el individualismo, en nuestro caso, hedonista y narcisista, es educar en la afectividad y el sentimiento, el placer inmediato, el narcisismo, la aculpabilidad, la novedad... y, en definitiva, pretender una educación que tenga como base el subjetivismo o esteticismo frente a un fuerte fundamento ético.

En expresión de J. Ma Lozano $(1991,30)$ la juventud actual ha sustituido la moral de la «brújula» por la moral del «radar». No se orientan con relación a un norte, sino que su punto de referencia es la posición de los demás. Van emitiendo y recibiendo signos y mensajes, a partir de los cuales van modificando constantemente su posición. Esta moral provisional del radar deja un amplio margen al presente, a la espontaneidad y provisionalidad, al azar de las cosas tal como van viniendo. No todo es igual, pero nada puede tener un fundamento estable y definitivo.

Fracasada la razón y roto el ser, ha nacido una nueva vida de su misma destrucción: la vida del sentimiento, la afectividad y el placer, el culto al cuerpo. Hemos de reconocer a la postmodernidad su acierto en valorar la afectividad -frente a la racionalidad moderna- por cuanto es el sentimiento y el afecto la dimensión humana que nos reporta un mayor grado de felicidad. La experiencia nos confirma que somos más felices cuando amamos que cuando sabemos o razonamos. Aspecto éste frecuentemente olvidado en el campo de la educación formal, en el cual la razón ha sido, y en buena parte continua siendo, la dueña y rectora de la educación frente a la esclava de la afectividad. La postmodernidad invertirá el orden, haciendo la esclava dueña y pasando la dueña a ser esclava. La moral, desde esta visión emotivista, no será otra cosa que «la expresión de unos sentimientos y unas actitudes, de nuestras preferencias por unas formas de conducta y nuestra desaprobación de otras. No hay una racionalidad, una razón de ser última e indiscutible de las virtudes» (Camps, 1990, 20).

De no menor importancia educativa es el valor del placer sensible e inmediato, en el cual el cuerpo ocupa un lugar muy especial y singular. Frente a la educación tradicional en la que el placer y el cuerpo eran infravalorados -y a veces hasta despreciados- en favor del esfuerzo, la razón o lo espiritual; la postmodernidad ha postulado el valor del placer y del cuerpo, despojándoles de sus visiones negativas para elevarlos a la categoría de «culto». De este modo, el cuerpo, y en muy poco tiempo, ha pasado de ser el enemigo del alma (según el antiguo catecismo: el mundo, el demonio y la carne) al objeto de «culto» o deidad, centro de la belleza, del placer y hasta del status social.

Si hemos de agradecer a la postmodernidad la recuperación de estos valores perdidos, no podemos dejar de interrogarnos sobre sus consecuencias individuales, sociales y educativas. 
Ciertamente la modernidad con su racionalismo mutiló la persona en detrimento del sentimiento; la postmodernidad ha hecho otro tanto, pero a la inversa: ha mutilado la razón a favor del sentimiento. Ambos extremos, por su unilateralidad, son igualmente desechables desde una visión armónica de la educación. Ni intelectualismo, ni sentimentalismo; más bien, sentimiento y razón. La integración armónica razón-afecto ha sido y es el reto de la educación. Zubiri $(1980,13)$ lo expresó acertadamente con la expresión «inteligencia sentiente». "Inteligir es el modo de sentir, y es en el hombre el modo de inteligir». Los monopolios, por cuanto conllevan de mutilación, son malos consejeros de la educación'; ni la tiranía de la razón, ni la tiranía del sentimiento.

Otro tanto cabe decir del hedonismo y narcisismo, el «pasarlo bien» a costa de todo, el cantar siempre y en todo momento -como la cigarra, despreocupada de todo- la alegría de vivir. La tarea de la educación es saber integrar el placer y el esfuerzo, la diversión y el compromiso, lo permanente y lo transitorio.

Sin esfuerzo, hoy por hoy, no es posible la educación, ni siquiera el aprendizaje de ciertas materias. Construirse como personas conlleva frecuentemente renuncias y sacrificios. Renunciar a todo esfuerzo en favor del placer -sin que éste, por supuesto, sea negativo en sí- es caminar con grandes posibilidades de viciarse, como ya expresó Von Cube en el I Symposion Internacional de Filosofía de la Educación. El título de su ponencia ya es suficientemente significativo: «Exigir en vez de mimar». En ella el profesor alemán se expresaba con estas palabras: «Bajo las modernas condiciones de vida, de la exonerable técnica y del bienestar material, el hombre ya no necesita entregarse a la búsqueda esforzada y peligrosa de la alimentación; ya no tiene que luchar por la pareja sexual; para satisfacer su curiosidad, ya no tiene que explorar el mundo con esfuerzos y peligros; él goza de la aventura del sillón. El hombre que puede satisfacer sus tendencias rápida y fácilmente, que está en condiciones de proporcionarse placer sin esfuerzo, brevemente tiene la posibilidad de viciarse» (Von Cube, 1988, 166).

El crecimiento de la violencia entre los jóvenes, el aumento del consumo de droga y del alcoholismo, son -en opinión de Von Cube- violencias contra sí mismo, consecuencias de una sociedad de consumo y bienestar, en la que el hombre «se ha dejado caer» al aspirar siempre a un placer sin esfuerzo. Es más, la misma libertad humana, tan ansiada entre los jóvenes, queda atrofiada sin el hábito del esfuerzo. Sin éste, el ser humano está siempre a merced del viento que sopla, de aquello que más le gusta y agrada de modo inmediato, del último que le ofrece pasarlo bien «a cualquier precio».

Con lo expuesto, no queremos en modo alguno pretender una educación dura y fría. El placer es tan necesario como el esfuerzo. Sólo queremos manifestar que uno y otro son necesarios para la construcción equilibrada de la persona, pues «una renuncia duradera al placer, lo mismo que una evitación duradera del esfuerzo, conduciría a una mayor agresividad, también contra sí mismo» (Von Cube, 1988, 170). La educación no es un regalo, sino una conquista; es la carrera -«currículo»- de una persona «animal racional/pasional», necesitada lo mismo del placer que del esfuerzo para llegar a la meta.

9. Hoy, en la educación institucional, es una realidad el divorcio entre el ocio y el libro, el aula y el placer. Ha desaparecido la tendencia natural hacia el saber, la alegría y el gozo de la formación. Todo parece hacerse con la «violencia» de los exámenes o por el afán de los títulos. La sabiduría ha dejado de ser medio agradable para convertirse en fin necesario. Los educadores haremos bien en reflexionar en las propuestas de la postmodernidad. 
Si la educación ha de hacer más valioso el ser humano individual y socialmente, ha de alejarse igualmente de ambos extremos. El individualismo, por su unilateralidad, conlleva una minusvaloración de la sociedad, una exaltación de la libertad y un debilitamiento de la autoridad en todos los ámbitos: familiar, política, religiosa y educativa. Un individualismo radical, ¿no lleva por su misma dinámica a una lucha de todos contra todos, y no a la convivencia de todos con todos? Para la convivencia pacífica, ¿no es necesario algún proyecto supraindividual? Para construirse persona, ¿no son tan necesarios los valores sociales como los individuales? En una buena educación, ¿no ha de conjugarse la libertad con la autoridad?

El hedonismo, por su parte, al sobrevalorar el placer sensible, conlleva un debilitamiento de la voluntad, un desprecio al servicio y la autodisciplina, una dificultad para insertarse en una sociedad «dura» y competitiva, y una amenaza para alcanzar ese mínimo de consenso moral necesario para la convivencia. Al sobrevalorar el placer, ¿no quedan lesionados o aniquilados otros valores? El ansia de placer sin medida, como ya hemos indicado, ¿no puede conducirnos a la autodestrucción? ¿No es necesario un cierto esfuerzo para ser libres? ¿Es posible una buena educación basada siempre en los intereses y gustos del educando?

Creemos que ni Hegel, ni Nietzsche; ni Narciso, ni Dionisios son buenos modelos de educación. La dificultad radica en determinar en qué medida el hombre se debe a la sociedad y ésta al hombre, así como en qué medida se relacionan el placer y el esfuerzo. Tal coordinación y armonía resulta tan difícil como necesaria, siendo, en ciertos casos, imprescindible -como ya sucedió a Sócrates y a tantos mártires y héroes- sacrificar la vida en defensa de sus valores personales en pugna abierta con los sociales. Puestos a elegir, personalmente nos inclinamos por el predominio de la persona sobre la sociedad, por cuanto ésta, en nuestra opinión, debe estar al servicio del hombre, y no a la inversa. Desde estos presupuestos sólo será conveniente limitar los valores individuales cuando éstos, de modo directo y grave, incidan negativamente sobre los valores sociales. Dicho con otras palabras, es necesario alcanzar la máxima libertad individual con la mínimas ataduras o normas sociales, sean éstas políticas, familiares o escolares. A partir de aquí sólo cabe el respeto, el consenso ${ }^{10}$ y la tolerancia.

\section{BIBLIOGRAFÍA}

Ballesteros, J. (1989). Postmodernidad decadencia o resistencia, Tecnos, Madrid.

Barcellona, P. (1992). Postmodernidad y comunidad. El regreso de la vinculación social, Trotta, Madrid.

BAUDRILlaRd, J. (1991). Las estrategias fatales, Anagrama, Barcelona.

BERNSTEIN, R. (1992). The new constellation. The ethical-political horizons of modernity/postmodernity. MA: MIT Press, Cambridge.

BREZINKA, W. (1990). La educación en una sociedad en crisis, Narcea, Madrid.

10. «Todo consenso no es inicio de verdad; pero se supone que la verdad de un enunciado no puede dejar de suscitar consenso» (Lyotard, J. F., La condición postmoderna, o. c., p. 52). 
CAMPILlo, A. (1985). Adiós al progreso, Anagrama, Barcelona.

CAMPS, V. (1990). Virtudes Públicas, Espasa-Calpe, Madrid.

Cebrián, J. L. (1987). El tamaño del elefante, Alianza Editorial, Madrid.

Cioran, E. M. (1988). Adiós a la filosofía. Alianza Editorial, Madrid.

Colom, A. J. (1984). «Hacia nuevos paradigmas educativos: La Pedagogía de la Postmodernidad», en Studia Paedagogica, $\mathrm{n}^{\circ} 14$, julio-diciembre.

Colom, A. J. (1991). «Educación, Problemática axiológica e ideología juvenil», en Homenaje a Ricardo Marín. UNED, Madrid.

CuBE, V. F. (1988). Actas del I Symposion Internacional de Filosofía de L'educació. Universidad Autónoma de Barcelona.

DíAZ, C. (1985). Escucha postmoderno, Ediciones Paulinas, Madrid.

FinfielKRAUT, A. (1987). La derrota del pensamiento, Anagrama, Barcelona.

FOSTER, H. y otros (1985). La Postmodernidad, Kairós, Barcelona.

FULlAT, O. (1990). Viaje inacabado (La axiología educativa en la postmodernidad), CEAC, Barcelona.

GEERTZ, CLIFFORD y otros (1992). El surgimiento de la antropología postmoderna, Gedisa, Barcelona.

GERVILLA, E. (1992). «La educación en la cultura de la postmodernidad», en Cuestiones actuales sobre educación, UNED, Madrid.

GeRVILLA, E. (1992). «Postmodernidad: Valores y Educación», en Actas del II Congreso Internacional de Filosofía de la Educación, UNED, Madrid.

GeRvilla, E. (1993). Postmodernidad y educación. Valores y cultura de los jóvenes, Dykinson, Madrid.

GonZÁleZ-CARVAJAL, L. (1992). «Educar en un mundo postmoderno», en Educadores, $\mathrm{n}^{\circ} 161$.

HABERMAS, J. (1981). «Modernity versus postmodernity», New German Critique. 22.

HABERMAS, J. (1985). La Modernidad, un proyecto incompleto, Kairós, Barcelona.

HARVEY, D. (1990). The conditions of post-modernity: An enquiry into the origins of cultural change, MA: Blackwell, Cambridge.

HASSAN, I. (1987). The postmodern turn: Essays in postmodern theory and culture, Ohio State University Press, Columbus.

HEIDEGGER, M. (1990). Sendas perdidas, Losada, Buenos Aires.

Heller, A.-FehER, F. (1989). Políticas de la postmodernidad, Península, Barcelona.

JARAUTA, F. (ed.) (1986). La crisis de la razón, Universidad de Murcia.

JIMÉNEZ, A. (1989). «A vueltas con la postmodernidad: los rasgos de la sensibilidad postmoderna», en Proyección, ${ }^{\circ} 36$.

KANT, E. (1981). ¿Qué es la Ilustración? Filosofía de la Historia, F.C.E., México.

KLAPPENBACH, A. (1990). Etica y postmodernidad, Servicio de Publicaciones, Universidad Alcalá de Henares.

LATHER, P. (1992). «El postmodernisno y las políticas de ilustración», en Revista de Educación, $\mathrm{n}^{\circ} 297$. 
LIPOVETSKI, G. (1991). El Imperio de lo efímero, Anagrama, Barcelona.

LIPOVETSKI, G. (1990). La era del vacío, Anagrama, Barcelona.

LOZANO, J. M. (1989). «De la condición urbana como condición postmoderna», en Cuadernos de Orientación Familiar, $\mathrm{n}^{\circ} 114$.

LozANo, J. M. (1991). ¿De qué hablamos cuando hablamos de los jóvenes? Cristianisme I Justicia, Barcelona.

LYOTARD, J. F. (1987). La postmodernidad (explicada a los niños), Gedisa, Barcelona.

LYOTARD, J. F. (1989). La condición postmoderna. Cátedra, Madrid.

MARDONES, J. M. (1991). Postmodernidad y neoconservadurismo, Verbo Divino. Estella, Navarra.

MARdoneS, J. M. (1986). «Modernidad y postmodernidad», en Razón y Fe, nº 1056.

MARdoneS, J. M. (1988). El desafío de la postmodernidad al cristianismo, Sal Terrae, Santander.

MARDONES, J. M. (1989). «¿Qué es la postmodernidad?», en Cuadernos de Orientación Familiar, nº 114.

MUGUERZA, J. (1977). La razón sin esperanza, Taurus, Madrid.

ORTIZ-OSES, A. (1986). La nueva filosofía hermenéutica. Hacia una razón axiológica postmoder$n a$, Anthropos, Barcelona.

PICó, J. (Comp.) (1988). Modernidad y Postmodernidad, Alianza Editorial, Madrid.

ROJAS, E. (1992). El hombre «light». Una vida sin valores, Temas de Hoy, Madrid.

RORTY, R. (1984). «Habermas and Lyotard on Postmodernity», en Praxis International, vol. IV, $\mathrm{n}^{\circ} 1$.

Ruber DE Ventós, X. (1980). De la modernidad, Península, Barcelona.

SÁDABA, J. (1984). Saber vivir, Ediciones Libertarias, Madrid.

SÁDABA, J. (1991). Saber morir, Ediciones Libertarias, Madrid.

SAVATER, F. (1988). Etica como amor propio, Mondadori, Barcelona.

SubIRATS, E. (1985). La Ilustración insuficiente, Taurus, Madrid.

Tierno Galván, E. (1976). ¿Qué es ser agnóstico?, Tecnos, Madrid.

Trimarco, A. (1991). Escapar de la postmodernidad, Julio Ollero Editor. Instituto de Estética, Madrid.

UMBRAL, F. (1988). Guía de la postmodernidad, Temas de Hoy, Madrid.

VARIOS (1986). La postmodernidad, Kairós, Barcelona.

VATTIMO, G. (1987). El fin de la modernidad. Nihilismo y hermenéutica en la cultura postmoder$n a$, Gedisa, Barcelona.

VATtimo G. y otros (1990). En torno a la postmodernidad, Anthropos, Barcelona.

VAtTimo, G.-RovatTi, P. A. (1988). El pensamiento débil, Cátedra, Madrid.

VAtтimo, G. (1990). La sociedad transparente, Paidós, Buenos Aires.

VATtimo, G. (1992). La secularización de la filosofía. Hermenéutica y postmodernidad, Gedisa, Barcelona.

Vicente Delgado, A. (1989). El arte en la Postmodernidad: Todo vale, Ediciones del Drac, Barcelona.

ZUBIRI, X. (1980). Inteligencia sentiente, Alianza Editorial, Madrid. 